\title{
Theoretical Analysis and Simulation Calculation of Three-row-roller Slewing Bearings Stiffness
}

\author{
Cheng Zhou ${ }^{1, a}$, Cungui YU ${ }^{2, b}$ \\ ${ }^{1}$ Engineering Training Center, Nanjing Univ Sci \& Technol, Nanjing 210094, China \\ ${ }^{2}$ School of Mechanical Engineering. Nanjing Univ Sci \& Technol, Nanjing 210094, China
}

Keywords: Hertz Contact theory; Three-row-roller; Stiffness; Finite Element

\begin{abstract}
Hertz contact theory and experimental methods are respectively adopted to analyze and study the relationship between the load and the axial stiffness, the radial stiffness and the overturning stiffness of the three-row-roller slewing bearings. The axial stiffness, the radial stiffness and the overturning stiffness of the three-row-roller slewing bearings are theoretically analyzed on the basis of Hertz contact theory. The finite element simulation calculation model of the bearing was established to verify the validity of the theoretical stiffness analysis. The theoretical analysis of the stiffness are approximately consistent with the results of the finite element simulation calculation. The oretical analysis and experimental result show: the axial stiffness, the radial stiffness and the overturning stiffness of the three-row-roller slewing bearings present nonlinear change rule ; Rigidity value are increased along with load increase and the tendency of the increase is gradually reduced.
\end{abstract}

\section{Introduction}

Three-row-roller slewing bearings, as a kind of new bearings with high bearing capacity, are mainly applied to complex large-load occasions. Fig.1 is the structure diagram of the external teeth type three-row-roller slewing bearings mainly composed of external ring, upper and lower inner rings, axial rollers at upper row, axial rollers at lower row and radial rollers. The axial force and the overturning moment applied thereto are borne by the axial rollers at upper and lower rows, and the radial force is borne by the radial rollers.

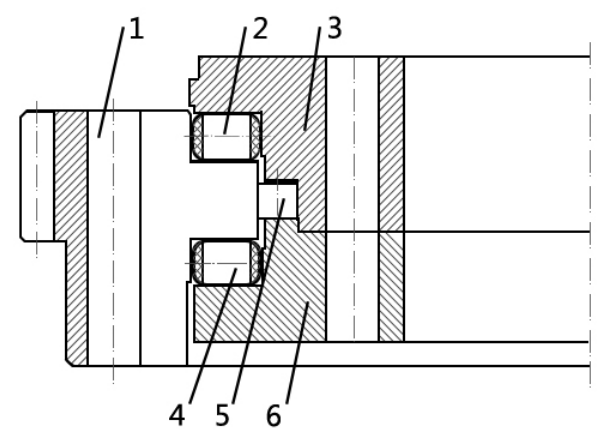

1-outer ring;2-upper row axial roller;3-upper inner ring;4-lower row axial roller;

5-radial roller;6-lower inner ring

Fig. 1. The schematic diagram of the structure of external three-row-roller slewing bearings

Currently, most literatures are mainly based on Hertz contact theory to study the stiffness of roller bearings, angular contact ball bearings and single-row bearings [1-6]. In terms of three-row-roller slewing bearings, Peter[7-8] proposed that a new computational model for determination of internal contact forces distribution and consequently the determination of acceptable load curves for static load capacity in three-row-roller slewing bearings 。 Peter[9] proposed that a calculation model for fatigue lifetime determination of a three-row-roller slewing bearing raceway. Josu[10] proposed that the derivation of the general static load-carrying capacity of three-row-roller slewing bearings under axial load and tilting-moment. This calculation is a true generalization of Rumbarger's method and provides an acceptance curve in the load space. In this 
paper, the three-row-roller slewing bearings stiffness will be studied.

\section{Theoretical Analysis of Bearings Stiffness}

\section{Condition hypothesis}

According to the working conditions of the three-row-roller slewing bearings, the following hypotheses are provided for the theoretical stiffness analysis: (1) the rollers are isotropous linear elastomers, so the rollers are assumed to be always in small deformation state under external force; (2) the overall deformation of the bearings are too small to be ignored; (3) the rotational motion of the bearings during artillery emission process is extremely small, so the additional load produced by the bearings is ignored; (4) the friction force between the rollers and the roller path is also ignored.

\section{Roller line contact stiffness analysis}

The rollers of the three-row-roller slewing bearings are cylinders and have line contact with the roller path. Hertz contact theory is adopted to deduce the formula for the amount of elastic deformation of the line contact. Fig.2 is the line contact diagram for two cylinders, and Fig.3 is the contact stress distribution diagram. $P$ is the load borne by the cylinders, $L$ is the cylinder length, $\mathrm{q}$ ( $\mathrm{q}=\mathrm{P} / \mathrm{L}$ ) is the line load distributed along the generatrix, $R 1$ and $R 2$ are the ellipse radiuses, $v 1 \& v 2$ and E1 \& E2 are respectively Poisson's ratios and elasticity moduli of two cylinders, $p_{0}$ is the maximum contact stress (length of major axis of the ellipse) and $a$ is the half-width of the contact surface (length of minor axis of the ellipse).

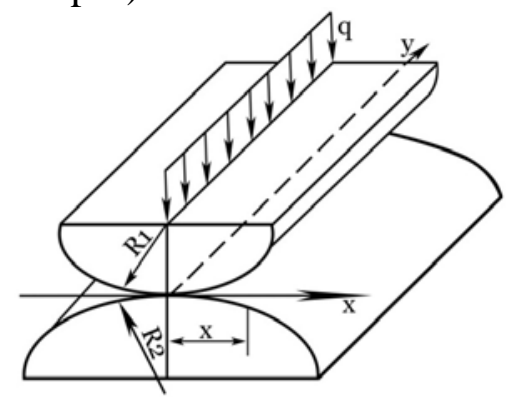

Fig. 2. the schematic diagram of the line contact

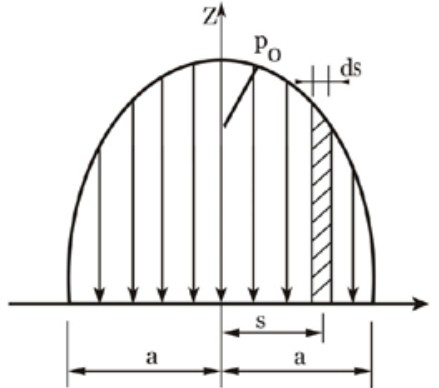

Fig. 3. the schematic diagram of contact stress distribution

Compatibility equation of Hertz line contact problem is as shown in Formula (1) [11]:

$\frac{2 \eta}{\pi} P V \int_{-a}^{a} \frac{p(s)}{x-s} d s=\frac{x}{R}$

Where:

$\eta=\frac{1-v_{1}^{2}}{E_{1}}+\frac{1-v_{2}^{2}}{E_{2}}$

$\frac{1}{R}=\frac{1}{R_{1}}+\frac{1}{R_{2}}$

$P V \int_{-a}^{a} \frac{p(s) d s}{x-s}=\lim _{\varepsilon \rightarrow 0}\left\{\int_{-a}^{x-\varepsilon} \frac{p(s) d s}{x-s}+\int_{x+\varepsilon}^{a} \frac{p(s) d s}{x-s}\right\}$

Contact equilibrium equation is as shown in Formula (2) [11]:

$\int_{-a}^{a} p(s) d s=q$ 
The line contact problem can be concluded to find a contact stress in the interval of [-a, a] to satisfy Formulae (1) and (2) according to elliptical distribution $p(s)$. Semi-elliptic functional equation is as shown in Formula (3):

$$
p(s)=\frac{p_{0}}{a} \sqrt{a^{2}-s^{2}}
$$

Formula (3) is put into Formulae (1) and (2) to obtain:

$$
\begin{aligned}
& \frac{2 p_{0} \eta}{\pi a} P V \int_{-a}^{a} \sqrt{\frac{a^{2}-x^{2}}{x-s}} d s=\frac{x}{R} \\
& \frac{p_{0}}{a} \int_{-a}^{a} \sqrt{a^{2}-s^{2}} d s=q
\end{aligned}
$$

The following formulae can be obtained through integral.

$$
\begin{aligned}
& a=\sqrt{\frac{4 R q \eta}{\pi}} \\
& p_{0}=\sqrt{\frac{q}{\pi \eta R}}
\end{aligned}
$$

In literature [12], normal contact deformation formula [13] of common smooth elastomer is referred to deduce normal contact deformation formula (8) for the line contact elastmoer on the basis of Hertz line contact theory:

$\delta=\eta \operatorname{pap}_{0} K$

Where $K$ is the first species of the complete elliptic integral, expressed as $K=\int_{0}^{\frac{\pi}{2}} \frac{1}{\sqrt{\cos ^{2} \theta+\varepsilon^{2} \sin ^{2} \theta}} d \theta$ which cannot be directly integrated, but when $\varepsilon$ is a small value, equivalent interpolation can be found for approximate calculation to finally find $K=\ln (3.862 / \varepsilon)$ $(\varepsilon=4 a / 3 L)$. Afterwards, $K=\ln (3.862 / \varepsilon)$ and Formulae (6) and (7) are put in Formula (8) to deduce the elastic deformation formula for the finite-length line contact, as shown in Formula (9):

$$
\delta=\frac{\eta P}{\pi L} \ln \frac{2.0974 L^{3}\left(R_{1} \pm R_{2}\right)}{\eta P R_{1} R_{2}}
$$

\section{Theory Analysis and Simulation Results Analysis}

The same bearing structure parameters and stress values were adopted and were substituted into stiffness theory calculation formula and finite element model respectively. Axial stiffness, radial stiffness, turning stiffness calculation results were as shown in table $1 \sim$ table3 respectively. The displacement curve with the change of load and the stiffness curve with the change of load were as shown in Fig $4 \sim$ Fig 9.

Table 1 Axial stiffness results comparison

\begin{tabular}{|c|c|c|c|c|c|}
\hline $\begin{array}{c}\text { Axial } \\
\text { load/N }\end{array}$ & $\begin{array}{c}\text { Theoretical axial } \\
\text { displacement/um }\end{array}$ & $\begin{array}{c}\text { Finite element axial } \\
\text { displacement/um }\end{array}$ & $\begin{array}{c}\text { Theoretical axial } \\
\text { stiffness/(N/um) }\end{array}$ & $\begin{array}{c}\text { Finite element axial } \\
\text { stiffness/(N/um) }\end{array}$ & $\begin{array}{c}\text { The ratio of theory } \\
\text { to finite } \\
\text { element/(\%) }\end{array}$ \\
\hline 0 & 25 & 25 & 0.00 & 0.00 & 0 \\
\hline $5 \times 103$ & 25.22 & 25.25 & 22727.27 & 20000.00 & 13.64 \\
\hline $5 \times 104$ & 26.89 & 27.13 & 26455.03 & 23474.18 & 12.70 \\
\hline $1 \times 105$ & 28.57 & 28.99 & 28011.20 & 25062.66 & 11.76 \\
\hline $2 \times 105$ & 31.73 & 32.27 & 29717.68 & 27510.32 & 8.02 \\
\hline $4 \times 105$ & 37.63 & 38.35 & 31670.63 & 29962.55 & 5.70 \\
\hline $6 \times 105$ & 43.23 & 43.88 & 32912.78 & 31779.66 & 3.57 \\
\hline $8 \times 105$ & 48.63 & 49.14 & 33855.27 & 33140.02 & 2.16 \\
\hline $1 \times 106$ & 53.88 & 54.46 & 34626.04 & 33944.33 & 2.01 \\
\hline
\end{tabular}


Table 2 Radial stiffness results comparison

\begin{tabular}{|c|c|c|c|c|c|}
\hline $\begin{array}{c}\text { Radial } \\
\text { load/N }\end{array}$ & $\begin{array}{c}\text { Theoretical radial } \\
\text { displacement/um }\end{array}$ & $\begin{array}{c}\text { Finite element radial } \\
\text { displacement/um }\end{array}$ & $\begin{array}{c}\text { Theoretical radial } \\
\text { stiffness/(N/um) }\end{array}$ & $\begin{array}{c}\text { Finite element radial } \\
\text { stiffness/(N/um) }\end{array}$ & $\begin{array}{c}\text { The ratio of theory } \\
\text { to finite } \\
\text { element/(\%) }\end{array}$ \\
\hline 0 & 20 & 20 & 0.00 & 0.00 & 0 \\
\hline $5 \times 103$ & 22.71 & 23.16 & 1845.02 & 1582.28 & 16.61 \\
\hline $5 \times 104$ & 32.44 & 34.40 & 4019.29 & 3472.22 & 13.76 \\
\hline $1 \times 105$ & 40.16 & 42.82 & 4960.32 & 4382.12 & 11.67 \\
\hline $2 \times 105$ & 53.34 & 57.23 & 5998.80 & 5372.01 & 7.74 \\
\hline $4 \times 105$ & 76.32 & 80.68 & 7102.27 & 6591.96 & 7391.89 \\
\hline $6 \times 105$ & 97.36 & 101.17 & 7755.95 & 8047.48 & 4.93 \\
\hline $8 \times 105$ & 117.28 & 119.41 & 8223.68 & 8459.52 & 2.19 \\
\hline $1 \times 106$ & 136.43 & 138.21 & 8588.85 & 1.53 \\
\hline
\end{tabular}

Table 3 Overturning stiffness results comparison

\begin{tabular}{|c|c|c|c|c|c|}
\hline $\begin{array}{c}\text { Overturning } \\
\text { moment } \\
/ \mathrm{Nm}\end{array}$ & $\begin{array}{c}\text { Theoretical angular } \\
\text { displacement/rad }\end{array}$ & $\begin{array}{c}\text { Finite element angular } \\
\text { displacement/rad }\end{array}$ & $\begin{array}{c}\text { Theoretical turning } \\
\text { stiffness/(Nm/rad) }\end{array}$ & $\begin{array}{c}\text { Finite element turning } \\
\text { stiffness/(Nm/rad) }\end{array}$ & $\begin{array}{c}\text { The ratio of } \\
\text { theory to finite } \\
\text { element/(\%) }\end{array}$ \\
\hline $5 \times 103$ & $2.78 \times 10-6$ & $3.23 \times 10-6$ & $1.799 \times 109$ & $1.548 \times 109$ & 16.19 \\
\hline $5 \times 104$ & $2.30 \times 10-5$ & $2.60 \times 10-5$ & $2.174 \times 109$ & $1.923 \times 109$ & 13.04 \\
\hline $1 \times 105$ & $4.31 \times 10-5$ & $4.81 \times 10-5$ & $2.320 \times 109$ & $2.079 \times 109$ & 11.60 \\
\hline $2 \times 105$ & $8.05 \times 10-5$ & $8.78 \times 10-5$ & $2.484 \times 109$ & $2.278 \times 109$ & 9.07 \\
\hline $4 \times 105$ & $1.49 \times 10-4$ & $1.57 \times 10-4$ & $2.685 \times 109$ & $2.548 \times 109$ & 5.37 \\
\hline $6 \times 105$ & $2.14 \times 10-4$ & $2.25 \times 10-4$ & $2.804 \times 109$ & $2.667 \times 109$ & 5.14 \\
\hline $8 \times 105$ & $2.76 \times 10-4$ & $2.84 \times 10-4$ & $2.899 \times 109$ & $2.817 \times 109$ & 2.90 \\
\hline $1 \times 106$ & $3.35 \times 10-4$ & $3.41 \times 10-4$ & $2.985 \times 109$ & $2.933 \times 109$ & 1.79 \\
\hline
\end{tabular}
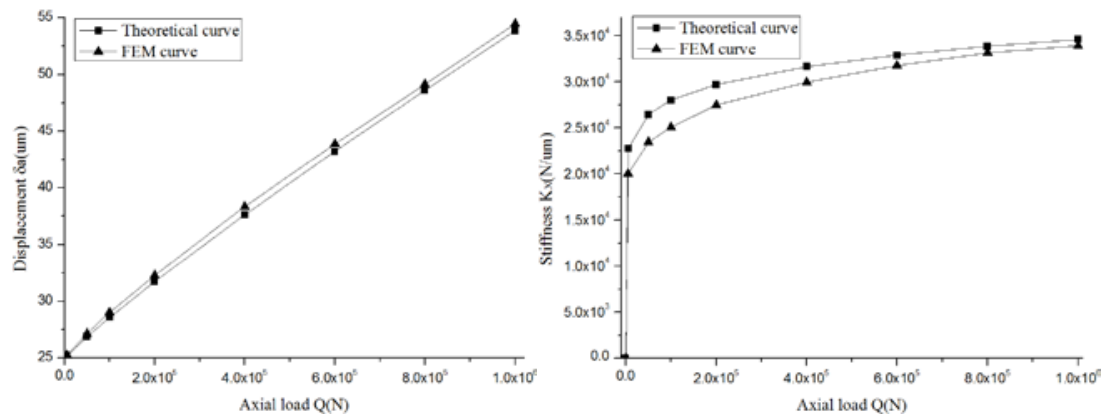

Fig. 4. Axial load - displacement curve Fig. 5. Axial load - stiffness curve
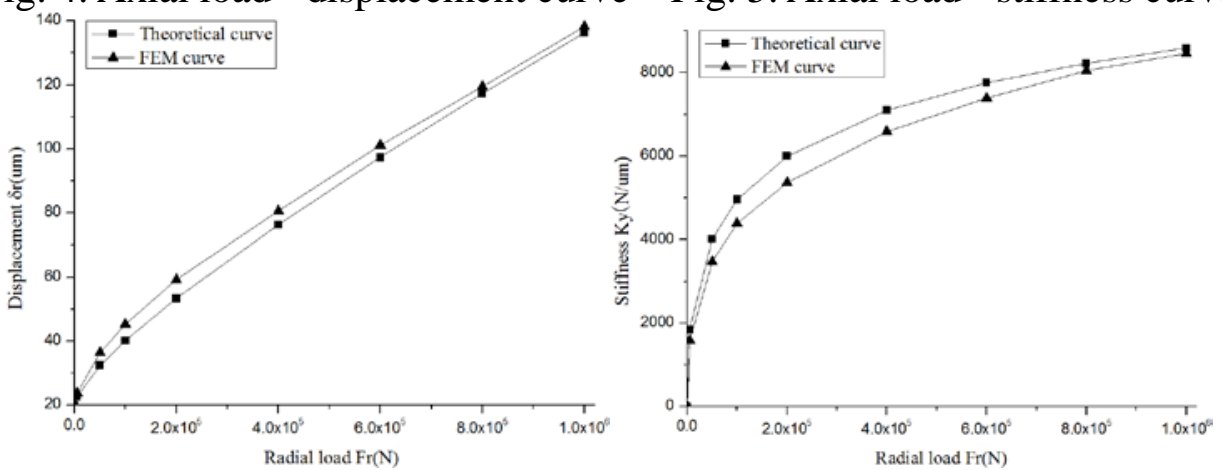

Fig. 6. Radial load - displacement curve Fig. 7. Radial load - stiffness curve 

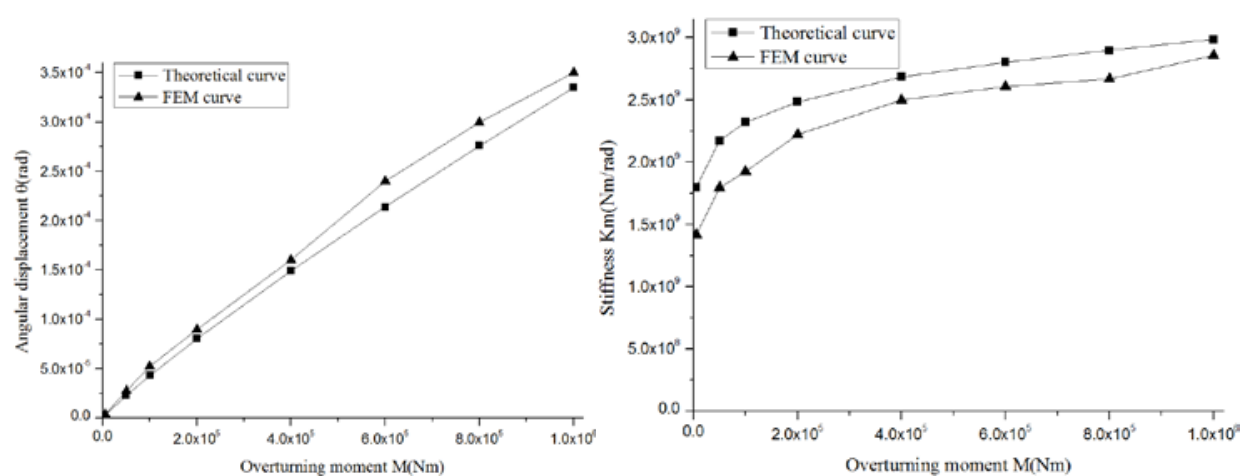

Fig. 8. Overturning moment-Angular displacement curveFig. 9. Overturning moment - stiffness

Table 1, Fig 8 and Fig 9 showed the axial stiffness rules of theory and finite element calculation rules were consistent with the change of load, and the axial stiffness was nonlinear. Stiffness increased as the load increased, but the increased trend was more and more smooth. When the axial load was less than $1 \times 105 \mathrm{~N}$, the difference ratio of the theory and finite element analysis results was over $10 \%$; When the load was greater than $1 \times 105 \mathrm{~N}$, the difference ratio was below $10 \%$. With the increase of load, the difference ratio between both decreased, but when the load was $1 \times 106$, the difference ratio was only $2.01 \%$.

Table 2, Fig 10 and Fig 11 showed radial stiffness rules of theory and finite element calculation was consistent with the change of load, radial stiffness was nonlinear, and nonlinear characteristics were obvious. The radial load displacement curve can clearly show the change of the slope, the stiffness increased with the increase of load, and stiffness changed greatly. When radial load was less than $4 \times 105 \mathrm{~N}$, the difference ratio of the theory and finite element analysis results was over $10 \%$; When the load was greater than $4 \times 105 \mathrm{~N}$, the difference ratio was below $10 \%$. With the increase of load, the difference ratio between both decreased, but when the load was $1 \times 106 \mathrm{~N}$, the difference ratio was only $1.53 \%$.

Table 3, Fig 12 and Fig 13 showed the turning stiffness rules of theory and finite element calculation were consistent with the change of the load, turning stiffness was nonlinear. Stiffness increased with the increase of moment, but the increased trend was more and more smooth. When turning moment was less than $2 \times 105 \mathrm{Nm}$, the difference ratio of theory and finite element analysis results was over $10 \%$; When the load was greater than $2 \times 105 \mathrm{Nm}$, the difference ratio was below $10 \%$, With the increase of the load, the difference ratio between both decreased, but when the load was $1 \times 106 \mathrm{~N}$, the difference ratio was only $1.79 \%$.

Axial stiffness, radial stiffness and turning stiffness increased with the increase of load. This is because roller and raceway had line contact when loaded initially. With the increase of load, the contact between the roller and raceway was changed into surface contact from line contact, and the contact area became bigger, causing the larger stiffness. Especially radial stiffness changed greatly, the reason was that the existence of the radial clearance led to different number of loaded rollers when there is different load. The greater the load was, the more rollers which are loaded, the greater the radial stiffness amplification was, through the combination of the increase of loaded rollers and the increase of contact area.

The theoretical analysis calculation result was greater than the finite element simulation calculation result, the reason was that many assumptions were made, some deformation was ignored in the theoretical analysis, while the deformation factors were considered during the finite element simulation analysis and calculation, so the stiffness value through finite element calculation was smaller than the theoretical value. In addition, the smaller the grid was theoretically, the smaller the more accurate the calculation result was during the the finite element calculation, but due to the limitation of computing power, grid can't be infinitely small, which also led to the difference between finite element calculation results and theoretical calculation results. With the increase of load, the difference value between both became smaller. This was because with the increase of load, the proportion of ignored deformation got smaller relative to the whole deformation, and both calculation results were increasingly closer. 


\section{Conclusion}

(1) Theoretical analysis and finite element simulation analysis calculation results showed that there was the nonlinear relation between axial stiffness, radial stiffness and turning stiffness of three-row-roller slewing bearings. With the increase of load, stiffness value increased, and the increased trend slowed gradually.

(2) Theory analysis and finite element simulation analysis and calculation results of axial stiffness, radial stiffness, overturning stiffness were closer, with consistent law, but there was a certain error. With the increase of load, the proportion of ignored deformation got smaller relative to the whole deformation, and the difference between finite element calculation results and theoretical calculation results became smaller.

(3) Its structure characteristic of three-row-roller slewing bearings was that gun firing load that bearing undertook was up to $5 \times 105 \mathrm{~N}$, when it was applied to the overloading environment, such as truck-mounted artillery. The theoretical analysis and finite element simulation analysis calculation results comparison showed when outer load was larger ( for example, axial load was greater than $1 \times 105 \mathrm{~N}$, the radial load greater than $2 \times 105 \mathrm{~N}$, turning moment greater than $1 \times 105 \mathrm{Nm}$ ), the relative error between theoretical analysis and finite element simulation analysis calculation results was within $10 \%$, and theoretical analysis calculation results can satisfy the need of practical application.

\section{References}

[1] Wan,C.S., Analysis of rolling element bearings. London:Mechanical Engineering Publications Limited,1991.

[2] Szuminski,P., Determination of the stiffness of rolling kinematicpa-irs of manipulators. Mechanism and Machine Theory, vol.42,no.9,pp.1082-1102,2007.

[3] Gunduz,A.; Singh,R., Stiffness matrix formulation for double rowangular contact ball bearings:analytical development and validation. Journal of Sound and Vibration, vol.332,no.22,pp.5898-5916,2013.

[4] Chen,Y.X.; Wang,G.B.; Yang,S.N., Analysis of dynamic stiffness of cylindrical roller bearing. bearing,vol.4,pp.1-5,2007.

[5] Li,W.G.; Pan,C.Y.; Wang,R.J., Stiffness analysis of hollow cylindric-al roller bearing. Chinese mechanical engineering, vol.20,no.7,pp.795-798,2009.

[6] Huang,D.S.; Gu,K.Q., Nonlinear stiffness analysis of crossed roller slewing bearing. Mechanical manufacturing and automation, vol.42,no.5, pp.19-23,2013. 